Published in final edited form as:

Chem Res Toxicol. 2016 March 21; 29(3): 323-332. doi:10.1021/acs.chemrestox.5b00485.

\title{
Covalent Modification of CDK2 by 4-Hydroxynonenal as a Mechanism of Inhibition of Cell Cycle Progression
}

\author{
Jeannie M. Camarillo ${ }^{\dagger}$, Kristie L. Rose ${ }^{\ddagger}$, James J. Galligan ${ }^{\dagger}$, Shu $\mathrm{Xu}^{\dagger}$, and Lawrence J. \\ Marnett ${ }^{\star}, \dagger, \S, \#, \perp$ \\ ${ }^{\dagger}$ A.B. Hancock Jr. Memorial Laboratory for Cancer Research, Department of Biochemistry, \\ Vanderbilt University School of Medicine, Nashville, Tennessee 37232-0146, United States \\ $\S$ Department of Chemistry, Vanderbilt University School of Medicine, Nashville, Tennessee \\ 37232-0146, United States \\ \#Department of Pharmacology, Vanderbilt University School of Medicine, Nashville, Tennessee \\ 37232-0146, United States \\ ¥Mass Spectrometry Research Center, Vanderbilt University School of Medicine, Nashville, \\ Tennessee 37232-0146, United States \\ ${ }^{\perp}$ Vanderbilt Institute of Chemical Biology, Center in Molecular Toxicology, Vanderbilt-Ingram \\ Cancer Center, Vanderbilt University School of Medicine, Nashville, Tennessee 37232-0146, \\ United States
}

\begin{abstract}
Oxidative stress is a contributing factor in a number of chronic diseases, including cancer, atherosclerosis, and neurodegenerative diseases. Lipid peroxidation that occurs during periods of oxidative stress results in the formation of lipid electrophiles, which can modify a multitude of proteins in the cell. 4-Hydroxy-2-nonenal (HNE) is one of the most well-studied lipid electrophiles and has previously been shown to arrest cells at the G1/S transition. Recently, proteomic data have shown that HNE is capable of covalently modifying CDK2, the kinase responsible for the G1/S transition. Here, we identify the sites adducted by HNE using recombinant CDK2 and show that HNE treatment suppresses the kinase activity of the enzyme. We further identify sites of adduction in HNE-treated intact human colorectal carcinoma cells (RKO) and show that HNE-dependent modification in cells is long-lived, disrupts CDK2 function, and correlates with a delay of progression of the cells into S-phase. We propose that adduction of CDK2 by HNE directly alters its activity, contributing to the cell cycle delay.
\end{abstract}

\section{Graphical abstract}

\footnotetext{
*Corresponding Author Phone: 615-343-7329. Fax: 615-343-7534. larry.marnett@ vanderbilt.edu. Supporting Information

The Supporting Information is available free of charge on the ACS Publications website at DOI: 10.1021/acs.chemrestox.5b00485. $\mathrm{MS}^{2}$ spectra of adducted peptides from recombinant CDK2 and additional cell cycle graphs (PDF)

Notes

The authors declare no competing financial interest.
} 


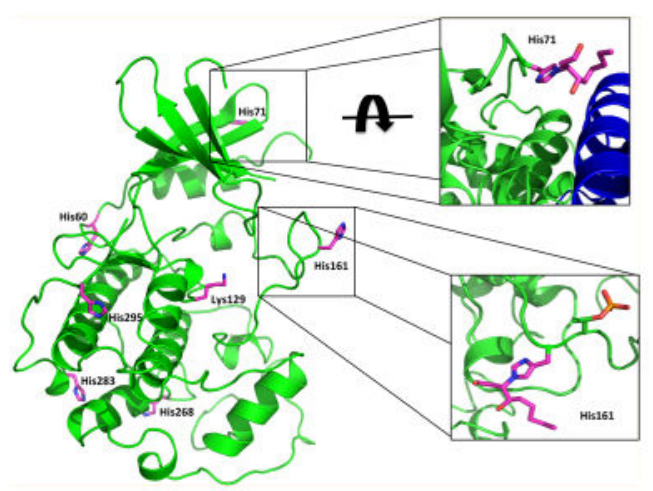

\section{INTRODUCTION}

Oxidative stress results from an imbalance between reactive oxygen species (ROS) generation and the antioxidant defenses of the cell and is a contributing factor in a number of diseases, including cancer, atherosclerosis, neurodegenerative disease, and asthma. ${ }^{1-4}$ ROS elicit their deleterious effects via reactions with cellular biomolecules, including proteins, DNA, and polyunsaturated fatty acids (PUFAs). ${ }^{5}$ The oxidation and subsequent decomposition of PUFAs result in the formation of reactive lipid aldehydes, such as 4hydroxy-2-nonenal (HNE). ${ }^{6}$ These lipid electrophiles are capable of forming covalent adducts with nucleophilic residues on proteins (i.e., Cys, His, and Lys), often proving detrimental to protein function. ${ }^{7,8}$

Cell cycle progression is a tightly controlled process involving a network of signaling events required to maintain genomic fidelity and prevent aberrant cell growth. CDK2 regulates the transition from G1- to S-phase and progression through S-phase via interactions with temporally expressed cyclin partners at different phases in the cell cycle. ${ }^{9,10}$ The interaction between CDK2 and Cyclin E in late G1-phase results in hyper-phosphorylation of Rb, a main tumor suppressor responsible for inhibiting DNA replication. This hyperphosphorylation causes the complete dissociation of the $\mathrm{Rb} / \mathrm{E} 2 \mathrm{~F} 1$ complex, allowing for E2F1-mediated expression of S-phase genes and entry into S-phase. ${ }^{11}$ During this time, Cyclin A is expressed, further modulating CDK2 activity; thus, Rb remains hyperphosphorylated throughout the S-phase. Under DNA damage conditions, Rb remains hypophosphorylated and bound to E2F1, thereby inhibiting cell cycle progression. ${ }^{12-14}$ The result is G1 arrest until the damage is repaired and the inhibitory signals are removed or the cell undergoes apoptosis.

Previous studies have investigated the role of lipid peroxidation products, specifically HNE, in the regulation of the cell cycle. ${ }^{15}$ Early studies in $S$. cerevisiae revealed that treatment with HNE inhibits cells from entering S-phase, suggesting a defect at the G1/S restriction point, and further studies in mammalian cells have yielded similar results. ${ }^{16}$ Treatment of human leukemia and neuroblastoma cell lines with HNE led to a halt in the cell cycle at G0/G1 by both p53-dependent and -independent mechanisms. ${ }^{17,18}$ In the p53 wild-type neuroblastoma cell line SK-N-BE, HNE increased levels of p53 and p21 after a $24 \mathrm{~h}$ treatment, resulting in G1 arrest. In the p53-deficient leukemic cell line HL-60, a rapid 
decrease in $\mathrm{Rb}$ phosphorylation coupled with an increase in $\mathrm{Rb} / \mathrm{E} 2 \mathrm{~F} 1$ complexes following HNE treatment is indicative of G1 arrest. In those cells, p21 was not induced until $12 \mathrm{~h}$ following HNE treatment, suggesting that a more immediate inhibition of G1-phase CDKs allowed for the maintenance of intact $\mathrm{Rb} / \mathrm{E} 2 \mathrm{~F} 1$ complexes through the suppression of $\mathrm{Rb}$ hyperphosphorylation.

Although these previous studies demonstrate a role for HNE in cell cycle inhibition, the precise mechanism leading to this inhibition remains unclear. Recently, we have utilized alkynyl HNE (aHNE), the $\omega$-alkyne analogue of HNE, to identify adducted cellular proteins. aHNE maintains the reactivity of HNE in cells, and it allows for posthoc biotinylation using click chemistry to selectively isolate modified proteins. ${ }^{19,20}$ Proteomic analysis identified CDK2 as a target of aHNE, and adduction increased with increased electrophile concentration linearly over the concentrations studied. ${ }^{21}$ Gene expression data from HNEtreated RKO cells provided further insight into pathways significantly altered by HNE treatment. A systems analysis approach that integrates proteomic and gene expression data revealed that treatment of cells with HNE not only results in modification of CDK2 but also leads to significant decreases in the genes controlled by CDK2 activation. ${ }^{22}$ These data suggest that HNE modification of CDK2 could result in cell cycle arrest at the G1/S-phase transition. Here, we show that modification of recombinant CDK2 by HNE disrupts its kinase activity. We identify the major sites of HNE-mediated CDK2 modification and use aHNE to define the time course of CDK2 adduction in cells. We further show that HNE inhibits CDK2 activity in intact cells, suggesting that HNE-mediated CDK2 kinase inactivation is a direct contributor to cell cycle disruption. Finally, we show that HNE delays entry into S-phase by a mechanism that does not depend on induction of p53 or p21, supporting a role for CDK2 inactivation in that process.

\section{METHODS}

\section{Materials and Reagents}

All reagents were purchased from Sigma-Aldrich (St. Louis, MO) unless otherwise stated. HNE, 8,9-alkynyl-HNE (aHNE), and UV-cleavable azido-biotin were synthesized in the laboratory of Dr. Ned Porter at Vanderbilt University as previously described. ${ }^{20}$ Cell culture medium and $1 \times$ Dulbecco's phosphate buffered saline (DPBS, $\mathrm{pH}$ 7.2) was purchased from Invitrogen (Grand Island, NY). Fetal bovine serum (FBS) was obtained from Atlas Biologicals (Ft. Collins, CO). Recombinant CDK2 protein was purchased from Abcam (Cambridge, MA), and CDK2-Cyclin E and CDK2-Cyclin A recombinant complexes were purchased from EMD Millipore (Billerica, MA). Anti-CDK2 (M2), anti-actin, and Protein A/G Plus Agarose Beads were from Santa Cruz Biotechnology (Santa Cruz, CA). AntipT160 CDK2 and anti-PARP antibodies were from Cell Signaling Technologies (Danvers, MA). Anti-cyclin E1 [HE12], anti-p27 KIP1, anti-Rb (phospho T821), anti-cyclin A2 [E23.1], and anti-p21 antibodies were purchased from Abcam. All SDS-PAGE and Western blot supplies were obtained from Bio-Rad (Hercules, CA) unless otherwise noted. Streptavidin sepharose high performance beads, $\gamma^{32} \mathrm{P}$-ATP, calf histone H1 protein, and dithiothreitol (DTT) were purchased from GE Life Sciences (Pittsburgh, PA), PerkinElmer 
(Santa Clara, CA), EMD Millipore, and Research Products International (Mt. Prospect, IL), respectively.

\section{Cell Culture and Treatments}

The human colorectal cancer cell line RKO was obtained from American Type Culture Collection (ATCC, Manassas, VA). Cells were cultured in Dulbecco's Modified Eagle Medium (DMEM) with $10 \% \mathrm{FBS}$ at $37{ }^{\circ} \mathrm{C}$ with $5 \% \mathrm{CO}_{2}$. Electrophiles were dissolved in DMSO and added to cell culture medium with a final concentration of less than $0.1 \%$ DMSO. Concentrations of HNE used in the studies were not cytotoxic as a result of the limited length of exposure and the high concentrations of glutathione in RKO cells. ${ }^{21,23}$

\section{Flow Cytometry for Cell Cycle Analysis}

Cells were serum-starved for $24 \mathrm{~h}$ to synchronize in G1/G0. Cells were then pretreated with $30 \mu \mathrm{M}$ HNE or DMSO for $1 \mathrm{~h}$ in serum-free medium followed by release into medium containing $10 \%$ FBS and harvested at the indicated times. During collection, cells were washed with $1 \times$ DPBS ( $\mathrm{pH} 7.2$ ), trypsinized, and washed a second time with $1 \times$ DPBS. Cells were fixed with ice-cold absolute ethanol overnight at $-20^{\circ} \mathrm{C}$ and then collected by centrifugation at $1000 \mathrm{~g}$ for $5 \mathrm{~min}$ and washed twice with $1 \times$ DPBS. Following resuspension in $1 \mathrm{~mL}$ of $1 \times$ DPBS, samples were incubated at $37^{\circ} \mathrm{C}$ for 15 min with $50 \mu \mathrm{L}$ of $1 \mathrm{mg} / \mathrm{mL}$ of RNase A, cooled to room temperature (RT), and stained with propidium iodide at a final concentration of $20 \mu \mathrm{g} / \mathrm{mL}$. Samples were stored at $4{ }^{\circ} \mathrm{C}$ in the dark and analyzed on a 3laser BD LSRII flow cytometer (BD Biosciences, Franklin Lakes, NJ).

\section{Protein Extraction}

Cells were scraped into medium, collected by centrifugation at $500 \mathrm{~g}$ for $5 \mathrm{~min}$, and washed twice with $1 \times$ DPBS. Cells were lysed for $10 \mathrm{~min}$ on ice in RIPA buffer [50 $\mathrm{mM}$ Tris $(\mathrm{pH}$ 7.4), $150 \mathrm{mM} \mathrm{NaCl}, 1 \% \mathrm{NP}-40,0.1 \% \mathrm{SDS}, 0.5 \%$ sodium deoxycholate, $1 \mathrm{mM}$ EDTA] containing protease and phosphatase inhibitors (Sigma-Aldrich, St. Louis, MO) and centrifuged at $16,000 \mathrm{~g}$ for $20 \mathrm{~min}$. The supernatant was collected, and the pellet was discarded. The BCA assay was used to determine protein concentrations according to the manufacturer's protocol (Thermo Fischer Scientific, Waltham, MA).

\section{Click Chemistry}

Cell lysates (1 mg of protein) were reduced with $20 \mathrm{mM} \mathrm{NaBH}_{4}$ and subjected to click chemistry according to a previously described method. ${ }^{21}$ Briefly, the lysates were incubated with $1 \mathrm{mM} \mathrm{CuSO}_{4}, 1 \mathrm{mM}$ tris(2-carboxyethyl)phosphine, $0.1 \mathrm{mM}$ tris(benzyltriazolylmethyl)amine, and $0.2 \mathrm{mM} \mathrm{UV}$-cleavable azido biotin for $2 \mathrm{~h}$ at RT with end-over-end mixing. Protein was precipitated with 2 volumes of ice-cold methanol and resolubilized in $0.5 \%$ SDS with sonication and mixing. Streptavidin beads were added overnight at $4{ }^{\circ} \mathrm{C}$ in the dark with end-over-end mixing, washed twice each with $1 \%$ SDS, 4 $\mathrm{M}$ urea, $1 \mathrm{M} \mathrm{NaCl}$ in $1 \times$ DPBS, and $1 \times$ DPBS, and adducted proteins were eluted in water under $365 \mathrm{~nm}$ UV light for $90 \mathrm{~min}$. Eluates were dried under nitrogen and resuspended in water. 


\section{SDS-PAGE and Western Blots}

Samples were denatured in $2 \times$ Laemmli sample buffer with $5 \% \beta$-mercaptoethanol and heated at $95{ }^{\circ} \mathrm{C}$ for $5 \mathrm{~min}$. Proteins were resolved by SDS-PAGE and transferred onto nitrocellulose membranes. Membranes were blocked in Odyssey Blocking Buffer (Li-Cor Biosciences, Superior, NE) for $1 \mathrm{~h}$ at RT, and primary antibodies were applied overnight at $4{ }^{\circ} \mathrm{C}$ in Odyssey Blocking Buffer. Membranes were washed three times in tris-buffered saline with Tween-20 (TBST), and infrared secondary antibodies (Li-Cor) were added at a 1:5000 dilution for $1 \mathrm{~h}$ at RT. Following three additional washes, blots were developed using the Odyssey Infrared Imaging System (Li-Cor).

\section{In-Solution Modification of Recombinant CDK2}

Recombinant CDK2 protein was diluted to $2.5 \mathrm{mg} / \mathrm{mL}$ in $1 \times$ DPBS. HNE (30 $\mu \mathrm{M})$ or DMSO (vehicle control) was added to the pure protein at the indicated concentrations and incubated for $1 \mathrm{~h}$ with gentle agitation at $37^{\circ} \mathrm{C}$. The reaction mixture was quenched with the addition of $\mathrm{NaBH}_{4}$ to a final concentration of $20 \mathrm{mM}$, reduced with $150 \mu \mathrm{M}$ DTT for $30 \mathrm{~min}$ at $37^{\circ} \mathrm{C}$, and alkylated with $750 \mu \mathrm{M}$ iodoacetamide for $15 \mathrm{~min}$ at RT in the dark. Samples were digested with $10 \mathrm{ng} / \mu \mathrm{L}$ of trypsin overnight and dried by vacuum centrifugation.

\section{Generation of CDK2-His}

Cdk2-HA was a gift from Sander van den Heuvel (Addgene plasmid \#1884). ${ }^{24}$ Cdk2 was PCR-amplified with the following primers to replace the C-terminal HA-tag with a Cterminal 6XHis-tag: forward 5' - CATCATGGATCCATGGAGAACTT-3' ${ }^{\prime}$, reverse $5^{\prime}$ TTATGAATTCTATCAATGGTGATGGTGATGGTGGAGTCGAAGATGGGGTA- $3^{\prime}$. The PCR product was digested with $B a m H I$ and $E c o$ RI and ligated into pcDNA3.1 (Invitrogen) for expression in mammalian cells (pcDNA3.1-CDK2-6XHis).

\section{Transfection and Purification of CDK2-His}

RKO cells were transfected with pcDNA3.1-CDK2-6XHis (10 $\mu \mathrm{g})$ with $10 \mu \mathrm{L}$ of Lipofectamine 2000 (Invtitrogen) in Opti-MEM medium for $24 \mathrm{~h}$, and then the medium was replaced with serum-free DMEM containing $250 \mu \mathrm{M}$ HNE for $1 \mathrm{~h}$. Cells were scraped in cold $1 \times$ DPBS and lysed on ice in His lysis buffer [50 mM sodium phosphate (pH 8.0), 300 $\mathrm{mM} \mathrm{NaCl}, 20 \mathrm{mM}$ imidazole, and $0.05 \%$ Tween-20] for $10 \mathrm{~min}$. Lysates were cleared by centrifugation at $16,000 \mathrm{~g}$ for $10 \mathrm{~min}$. Lysates were reduced with $20 \mathrm{mM} \mathrm{NaBH}_{4}$ for $15 \mathrm{~min}$ to stabilize adducts. Ni-NTA beads (Qiagen) were added to lysates and incubated with endover-end mixing for $2 \mathrm{~h}$ at $4{ }^{\circ} \mathrm{C}$. Beads were washed six times with His Lysis Buffer and then eluted with His elution buffer [ $50 \mathrm{mM}$ sodium phosphate (pH 8.0), $300 \mathrm{mM} \mathrm{NaCl}, 250$ $\mathrm{mM}$ imidazole, and $0.05 \%$ Tween-20] for $5 \mathrm{~min}$ at RT. Eluates were denatured in $2 \times$ Laemmli sample buffer with $5 \% \beta$-mercaptoethanol, heated at $95{ }^{\circ} \mathrm{C}$ for $5 \mathrm{~min}$, and proteins were resolved by SDS-PAGE. Following staining with Simply Stain (Invitrogen), bands corresponding to CDK2-His were excised and cut into $1 \mathrm{~mm}^{3}$ pieces. Gel pieces were treated with $45 \mathrm{mM}$ DTT for $45 \mathrm{~min}$ and carbamidomethylated with $100 \mathrm{mM}$ iodoacetamide for $45 \mathrm{~min}$. Following destaining with $50 \%$ acetonitrile in $25 \mathrm{mM}$ ammonium bicarbonate, $10 \mathrm{ng} / \mu \mathrm{L}$ of trypsin was added overnight at $37{ }^{\circ} \mathrm{C}$. Peptides were extracted by gel dehydration (60\% acetonitrile, $0.1 \%$ TFA) and dried by vacuum centrifugation. 


\section{Analysis of CDK2 Peptides by LC-MS/MS}

Following reconstitution in $0.1 \%$ formic acid, peptides were loaded onto a capillary reverse phase analytical column (360 $\mu$ m O.D. $\times 100 \mu$ m I.D.) using an Eksigent NanoLC Ultra HPLC and autosampler. The analytical column was packed with $20 \mathrm{~cm}$ of C18 reverse phase material (Jupiter, $3 \mu \mathrm{m}$ beads, $300 \AA$ A, Phenomenox) directly into a laser-pulled emitter tip. Peptides were gradient-eluted at a flow rate of $500 \mathrm{~nL} / \mathrm{min}$, and the mobile phase solvents consisted of $0.1 \%$ formic acid and $99.9 \%$ water (solvent A) and $0.1 \%$ formic acid and $99.9 \%$ acetonitrile (solvent B). A 90 min gradient was performed, consisting of the following: 0-10 $\mathrm{min}, 2 \% \mathrm{~B}$; 10-50 min, 2-40\% B; 50-60 min, 35-95\% B; 60-65 min, 95\% B; 65-70 min, 95-2\% B; and 70-90 min, 2\% B. Upon gradient elution, peptides were mass analyzed on a Thermo Scientific LTQ Orbitrap Velos mass spectrometer equipped with a nanoelectrospray ionization source. The mass spectrometer was operated using a data-dependent method with dynamic exclusion enabled. Full scan $(\mathrm{m} / \mathrm{z} 300-2000)$ spectra were acquired with the Orbitrap as the mass analyzer (resolution 60,000), and the ten most abundant ions in each MS scan were selected for fragmentation in the LTQ. An isolation width of $2 \mathrm{~m} / z$, activation time of $10 \mathrm{~ms}$, and $35 \%$ normalized collision energy were used to generate $\mathrm{MS}^{2}$ spectra. For identification of modified peptides, tandem mass spectra were searched with Sequest against a human database created from the UniprotKB protein database (www.uniprot.org). Variable modifications of +57.0214 on Cys (carbamidomethylation), +15.9949 on Met (oxidation), +158.1306 on Cys, His, and Lys residues (corresponding to the reduced Michael adduct of HNE), +141.1279 on Lys and Arg (corresponding to the reduced Schiff base adduct of $\mathrm{HNE}$ ), and +156.1150 on Lys (corresponding to the 4-ketoamide adduct) were included for database searching. Search results were assembled using Scaffold 3.0 (Proteome Software), and sites of modification were validated by manual interrogation of tandem mass spectra.

\section{In Vitro Modification of CDK2 for Activity Assays}

Recombinant CDK2 complexed with Cyclin E or Cyclin A (15 ng) was incubated with 30 $\mu \mathrm{M}$ HNE in kinase assay buffer [20 mM HEPES (pH 7.4), $10 \mathrm{mM} \mathrm{MgCl}_{2}$ ] at $37{ }^{\circ} \mathrm{C}$ for $1 \mathrm{~h}$ with gentle agitation. Samples were immediately subjected to in vitro kinase assays as described below.

\section{CDK2 Immunoprecipitation}

Immunoprecipitations were performed according to a previously established protocol. ${ }^{25}$ Briefly, $800 \mu \mathrm{g}$ of total cell lysate protein was immunoprecipitated using anti-CDK2 antibodies on ice for $3 \mathrm{~h}$ and then for $90 \mathrm{~min}$ with protein A/G agarose beads with end-overend mixing. CDK2-bound beads were collected and washed three times with RIPA buffer followed by three washes with kinase assay buffer containing $1 \mathrm{mM}$ DTT. Beads were resuspended in kinase assay buffer containing $1 \mathrm{mM}$ DTT and subjected to Western blotting or kinase assays.

\section{In Vitro Kinase Assays}

Kinase assays were adapted from previous methods. ${ }^{25}$ Histone $\mathrm{H} 1$ protein $(2 \mu \mathrm{g}), 50 \mu \mathrm{M}$ unlabeled ATP, $10 \mu \mathrm{Ci} \gamma^{32} \mathrm{P}$-ATP, and kinase assay buffer containing $1 \mathrm{mM}$ DTT were added to a final volume of $50 \mu \mathrm{L}$ for in vitro-modified samples and $25 \mu \mathrm{L}$ for CDK2 
immunoprecipitates. The reactions were incubated at RT for 20 min with shaking and stopped with the addition of $2 \times$ Laemmli sample buffer with $5 \% \beta$-mercaptoethanol. Samples were heated at $95{ }^{\circ} \mathrm{C}$ for $10 \mathrm{~min}$, cooled, and loaded onto a 4-20\% polyacrylamide gel. Following electrophoresis, radioactive histone $\mathrm{H} 1$ protein was detected with the Molecular Imager PharosFX System (BioRad, Hercules, CA). Images were quantitated with ImageJ (NIMH, Bethesda, MD). The gel was then stained with Simply Stain (Invitrogen) according to the manufacturer's protocol.

\section{RESULTS}

\section{HNE Modifies a Number of Sites on Recombinant CDK2}

For elucidating possible structural and functional implications of CDK2 adduction, the sites of modification were determined by tandem mass spectrometry. Recombinant CDK2 was modified in vitro with HNE, digested, and analyzed by LC-MS/MS. There were a number of peptides that showed a mass shift of $158.1306 \mathrm{~m} / \mathrm{z}$, corresponding to a reduced Michael adduct, following HNE treatment (Table 1). When sites of modification were mapped on a previously established crystal structure of CDK2 (1HCL), adducted sites were mainly localized to surface-exposed histidine residues (Figure 1A). Of note, His71 and His161 were modified by HNE. His71 lies on the cyclin-binding interface and hydrogen bonds with residues on both Cyclin E and Cyclin A (Figure 1B). His161 immediately follows Thr160, the key CDK2 phosphorylation site required for kinase activity (Figure 1C).

\section{HNE-Modified CDK2 in RKO Cells}

As noted above, prior work had demonstrated HNE-dependent CDK2 modification in the RKO colorectal cancer cell line. ${ }^{21}$ To verify the sites of CDK2 modification in cells, we transfected RKO cells with a His-tagged CDK2 construct, then treated the cells with HNE. Following isolation of His-tagged protein, we performed in-gel digestion and analyzed the peptides by LC-MS/MS (Table 2). As in the case of recombinant CDK2, His71 was identified as a site of modification (Figure 2A). Interestingly, Cys177 was also modified by HNE in cells (Figure 2B). This modification has previously been observed in the literature, ${ }^{26}$ though we did not observe it in recombinant protein, possibly due to oxidation of that cysteine residue during storage.

\section{HNE-Dependent Modification of CDK2 Temporally Correlates with Cell Cycle Arrest}

Because CDK2 is modified at a number of sites in vitro, we wanted to further verify its modification in cells and assess if CDK2 adduction by HNE could be contributing to previously observed cell cycle dysregulation. To determine if CDK2 is modified by HNE within the relevant time frame to alter the cell cycle, we employed the 8,9-alkynyl analogue of HNE, aHNE, and used click chemistry to evaluate the levels of modified CDK2 in cells. RKO cells synchronized in G1/G0 were treated with aHNE or DMSO for $1 \mathrm{~h}$ and released into $10 \%$ serum-containing medium to allow for cell cycle progression. Click chemistry, streptavidin pull-down, and UV-cleavage enabled selective isolation of adducted proteins. Western blot analysis of eluates showed persistent modification of CDK2 by aHNE up to 16 $\mathrm{h}$ (Figure 3). There was a decrease in adducted CDK2 over time, indicative of protein turnover or adduct reversal. These data show that CDK2 is modified rapidly in cells, and that 
the modification persists for a substantial time period, consistent with the hypothesis that the modification may lead to functional alterations affecting the role of CDK2 in cell cycle progression.

\section{HNE Treatment Decreases Kinase Activity in CDK2/Cyclin A Complexes in Vitro}

CDK2 phosphorylates a number of proteins in late G1 to promote cell cycle progression. ${ }^{11,27-29}$ Because HNE has previously been shown to inhibit the activity of another protein kinase, ERK1/2, ${ }^{30}$ we sought to investigate the possible effects of HNE on CDK2 kinase activity. To assess the functional impact of HNE modification, we determined changes in CDK2 kinase activity of recombinant CDK2-cyclin complexes following HNE exposure. CDK2/Cyclin E or CDK2/Cyclin A complexes were modified in vitro with HNE and subjected to radioactive kinase assays using histone $\mathrm{H} 1$ as a model substrate. ${ }^{25}$ As shown in Figure 4A, there was a significant decrease in histone $\mathrm{H} 1$ phosphorylation in CDK2/Cyclin A complexes (Figure 4B) treated with $30 \mu \mathrm{M}$ HNE, but not in CDK2/Cyclin E complexes, which exhibited a trend toward decreased activity that was not statistically significant (Figure 4C). These differences in the effects of HNE on CDK2 activity in the two complexes may be the result of structural differences in the way that each cyclin interacts with CDK2. Regardless of the mechanism, these data confirm that HNE modification can directly alter CDK2 activity.

\section{HNE Treatment Decreases CDK2 Activity in Cells}

To further investigate the functional implications of HNE adduction of CDK2 in the cell, we performed in vitro kinase assays utilizing endogenous CDK2-cyclin immunoprecipitates. Cells were arrested in G0/G1 with serum starvation, treated with HNE for $1 \mathrm{~h}$, then released into the cell cycle with the addition of medium containing $10 \%$ FBS. Cells were collected at various time points up to $12 \mathrm{~h}$ thereafter, lysed, and CDK2-cyclin complexes captured. As shown in Figure 5, phosphorylation of histone H1 was low in CDK2-cyclin immunoprecipitates isolated from cells harvested immediately following treatment with HNE (lanes 1 and 2). Kinase activity has substantially increased by $6 \mathrm{~h}$, but there is little difference in $\mathrm{H} 1$ phosphorylation between the control and HNE-treated cell immunoprecipitates until $8 \mathrm{~h}$ following release. At $8 \mathrm{~h}$ (lanes 5 and 6), HNE-treated CDK2 immunoprecipitates display significantly lower levels of kinase activity (Figure 5B). These data suggest that HNE treatment lowers the activity of CDK2 in a time-dependent fashion, possibly contributing to the delay in cell cycle progression.

\section{HNE Delays Entry into S-Phase}

Previous reports have shown that HNE inhibits cell growth via multiple mechanisms. ${ }^{18,31,32}$ To further elucidate the mechanism of inhibition, RKO cells were synchronized in G1/G0 by serum withdrawal, treated with HNE, and then released from cell cycle arrest with serumcontaining medium. As expected, cell cycle analysis showed a high percentage of cells arrested in G0/G1 following serum starvation (Figure 6A). After $8 \mathrm{~h}$ in serum-containing medium, cells treated with DMSO displayed an increase in the percent of cells in S-phase, whereas the percentage of HNE-treated cells in S-phase remained significantly lower. Although increasing in both sets of cultures by $12 \mathrm{~h}$, the percentage of S-phase cells continued to be significantly lower in those exposed to HNE than in controls. However, 
these differences in the percent of cells in S-phase were abolished at $16 \mathrm{~h}$, suggesting that HNE-treated cells have a delay in S-phase initiation.

\section{HNE Does Not Alter Levels of Total or Phosphorylated Cell Cycle Proteins}

We tested the hypothesis that alterations in the levels or phosphorylation state of one or more of the proteins involved in the G1/S transition could account for the HNE-mediated delay in S-phase entry. Western blot analysis did not reveal any differences in levels of total CDK2 in the presence or absence of HNE at the observed times (Figure 7). Phosphorylation of CDK2 at Thr160, which is required to activate CDK2 in G1-phase, ${ }^{33}$ also did not show any significant changes with treatment, nor did phosphorylation of Thr821 on Rb, a CDK2 target. Additionally, levels of Cyclin E and Cyclin A, both of which are required for CDK2 activity, were unchanged with treatment.

We further investigated levels of G1 inhibitory proteins to rule out inhibition of CDK2 by these damaging pathways. HNE is known to activate the p53 response pathway, upregulate p21, and induce apoptosis via caspase and PARP cleavage. ${ }^{34}$ Levels of p53 did not increase over the observed times (Figure 7), which is consistent with previous reports showing that p53 is not upregulated until $24 \mathrm{~h}$ following treatment. ${ }^{18}$ We also determined the levels of p21, which is canonically regulated by p53 but can also be induced in a p53-independent manner. ${ }^{35}$ Levels of p21 and p27, an additional G1 CDK inhibitor, remained unchanged in response to HNE, demonstrating that CDK2 is not being directly inhibited by this mechanism. Additionally, we did not observe PARP cleavage (data not shown), indicating that apoptosis was not being initiated during these observed times. Together, these data suggest that the observed delay into S-phase occurs independently of these S-phase inhibitory pathways.

\section{DISCUSSION}

Here, we investigated the impact of HNE modification on CDK2 function and cell cycle progression. Because CDK2 has previously been identified as a target of aHNE, ${ }^{21}$ we investigated the extent of CDK2 modification in RKO cells. Modified CDK2 was present up to $16 \mathrm{~h}$ following HNE exposure, though levels declined over time, consistent with turnover or reversal of adducts. Tandem mass spectrometry of HNE-treated recombinant CDK2 revealed a number of sites of modification (Table 1). The majority of adducts found were on surface-exposed histidine residues, likely due to their accessibility. A single lysine residue was also found to be modified, which is consistent with the lower reactivity of HNE toward lysine residues. ${ }^{36}$ Although CDK2 does contain cysteine residues, the preferred targets of electrophile modification, all but a single cysteine is disulfide bound. When sites of modification were determined in cells, Cys177 was shown as a target of HNE modification in addition to His71, which had been identified in vitro. Previous work by Weerapana et al. ${ }^{26}$ also demonstrated adduction of Cys 177 by HNE, further supporting the validity of this modification. The data suggest that His 71 and Cys177 represent the most readily accessible sites of modification in cells.

Of the seven modified residues, two appear to be in a location that could greatly impact CDK2 activity. Using published crystal structures of CDK2, we were able to model the HNE 
adducts on His71 (Figure 8A) and His161 (Figure 8B). His71 lies on the cyclin-binding interface. Crystal structures of CDK2 phosphorylated at Thr160 and in complex with Cyclin E or Cyclin A have revealed that His71 is capable of hydrogen bonding with both cyclins. ${ }^{37,38}$ As the CDK2-cyclin interaction is required for CDK2 activation, it is possible that disruption of this interaction could ultimately inhibit kinase activity. Consistently, we observe a reduction in the kinase activity of HNE-treated recombinant CDK2/Cyclin A complexes. In contrast, activity assays using recombinant CDK2/Cyclin E complexes did not show significant differences with HNE treatment. We hypothesize that these differences in the effects of HNE on CDK2/cyclin complex kinase activity result from the structural differences between Cyclin E and Cyclin A and their required points of contact with CDK2. The Cyclin A/CDK2 interaction requires two additional contact points with Thr72 and Gln73, both of which are not required for Cyclin E. ${ }^{38}$ These subtle differences in structure may account for the functional differences observed.

This His 161 HNE modification site is of significant interest due to its proximity to the activating phosphorylation site. Phosphorylation of Thr160 by CDK7/Cyclin H occurs in response to growth factor stimulation and results in a significant conformational change in the activation loop of CDK2. ${ }^{39}$ Previous studies have shown that adduction of a similar histidine residue on the activation loop of ERK1/2 results in decreased activity. ${ }^{30}$ Furthermore, Cyclin A is in contact with His161 in the active complex, and this interaction is not present in the complex with Cyclin E. These differences may contribute to the variances in HNE-mediated modification of kinase activity between CDK2/Cyclin A and $\mathrm{CDK} 2 /$ Cyclin E complexes in vitro. Notably, however, this site was not identified in intact cells, an observation that may correlate with the finding that HNE treatment had no effect on Thr160 phosphorylation of CDK2 in our model (Figure 7). Thus, it is not clear to what extent modification at this site may be important for the effects of HNE on cell cycle regulation in vivo.

Further evidence that $\mathrm{HNE}$ can negatively impact CDK2 signaling is shown in in vitro kinase assays. Activity assays using endogenous CDK2 from RKO cells show a decrease in histone $\mathrm{H} 1$ phosphorylation by immunoprecipitates from cells treated with HNE at $8 \mathrm{~h}$. Because of temporal regulation of CDK2, activity of CDK2 is very low at $0 \mathrm{~h}$ when the cells are arrested in G1; thus, no effect of HNE treatment is observed at that time. By $6 \mathrm{~h}$ after the addition of serum, substantial CDK2 activity could be measured, but no effect of HNE was observed. In contrast, at the $8 \mathrm{~h}$ time point, a significant decrease in activity was observed between CDK2 immunoprecipitates recovered from control versus HNE-treated cells. Notably, the $8 \mathrm{~h}$ time point correlates when control, but not HNE-treated cells, begin their progression into $\mathrm{S}$ phase. It is not clear why a reduction in CDK2 activity is not observed at $6 \mathrm{~h}$ after HNE treatment; however, our in vitro assays demonstrate that the effects of HNE differ depending on the CDK2/Cyclin complex formed. Thus, changes in post-translational modifications and/or binding partners during the CDK2 activation process may be responsible for these observed differences.

The most highly characterized substrate of CDK2 is Rb, phosphorylation of which inactivates its inhibitory effect on the E2F1 transcription factor. Thus, we expected to see that HNE treatment of RKO cells would result in a reduction of Rb phosphorylation at 
Thr821, a target site for CDK2. Although the data suggest a trend in reduced phosphorylation at 12 and $16 \mathrm{~h}$ after serum addition, the differences were not statistically significant. It is possible that this lack of change in phosphorylation is the result of compensatory CDK4/6-dependent phosphorylation. Although Thr821 is preferentially phosphorylated by $\mathrm{CDK} 2,{ }^{40} \mathrm{CDK} 4$ has been shown to phosphorylate this residue. ${ }^{41}$ It is also possible that the immunoblot-based assay used lacked adequate sensitivity to observe a change.

Our data built upon previous work on the effects of HNE on the cell cycle. ${ }^{15}$ Cell cycle analysis of G1/G0-synchronized RKO cells shows that HNE treatment delays entry into Sphase. Our data also show that this delay occurs in the absence of increases in the levels of $\mathrm{p} 53, \mathrm{p} 21$, and $\mathrm{p} 27$, suggesting that these inhibitory proteins do not play a primary role in initiating the failure to progress (Figure 7). We propose the following mechanism for CDK2 inhibition (Figure 9). Under normal conditions, CDK2 activation requires cyclin binding and phosphorylation of the activation loop. High levels of DNA damage promote activation of the p53 pathway, directly leading to the inhibition of CDK2 through the binding of p21. Our data suggest that covalent modification of CDK2 by HNE can immediately inhibit CDK2 activity. This mechanism of inactivation occurs via direct modification of CDK2 at multiple sites, thereby inhibiting kinase activity and delaying entry into S-phase. We hypothesize that CDK2 inactivation by adduction plays a role in the immediate cell cycle delay observed in response to HNE treatment, whereas p21, which is induced later, plays a longer-term role in the maintenance of genomic integrity during electrophile stress.

\section{Supplementary Material}

Refer to Web version on PubMed Central for supplementary material.

\section{ACKNOWLEDGMENTS}

The authors would like to thank Dr. Carol Rouzer for critical review of this manuscript.

Funding

This work was supported by the NCI F31 CA192861 (J.M.C.), R37 CA087819 (L.J.M.), R01 CA087819 (L.J.M.), NIEHS T32 ES007028 (J.M.C.), and P01 ES013125 (L.J.M.).

\section{ABBREVIATIONS}

$\begin{array}{ll}\text { HNE } & \text { 4-hydroxynonenal } \\ \text { CDK2 } & \text { cyclin-dependent kinase 2 } \\ \text { PUFA } & \text { polyunsaturated fatty acid } \\ \text { aHNE } & \text { alkynyl 4-hydroxynonenal } \\ \text { DPBS } & \text { Dulbecco's phosphate buffered saline } \\ \text { FBS } & \text { fetal bovine serum } \\ \text { DTT } & \text { dithiothreitol }\end{array}$



TBST tris-buffered saline with Tween-20
RT room temperature
DMSO dimethyl sulfoxide

\section{REFERENCES}

(1). Sayre LM, Zelasko DA, Harris PL, Perry G, Salomon RG, Smith MA. 4-hydroxynonenal-derived advanced lipid peroxidation end products are increased in alzheimer's disease. J. Neurochem. 1997; 68:2092-2097. [PubMed: 9109537]

(2). Yoritaka A, Hattori N, Uchida K, Tanaka M, Stadtman ER, Mizuno Y. Immunohistochemical detection of 4-hydroxynonenal protein adducts in parkinson disease. Proc. Natl. Acad. Sci. U. S. A. 1996; 93:2696-2701. [PubMed: 8610103]

(3). Dalle-Donne I, Giustarini D, Colombo R, Rossi R, Milzani A. Protein carbonylation in human diseases. Trends Mol. Med. 2003; 9:169-176. [PubMed: 12727143]

(4). Hussain SP, Hofseth LJ, Harris CC. Radical causes of cancer. Nat. Rev. Cancer. 2003; 3:276-285. [PubMed: 12671666]

(5). Marnett LJ, Riggins JN, West JD. Endogenous generation of reactive oxidants and electrophiles and their reactions with DNA and protein. J. Clin. Invest. 2003; 111:583-593. [PubMed: 12618510]

(6). Yin H, Xu L, Porter NA. Free radical lipid peroxidation: Mechanisms and analysis. Chem. Rev. 2011; 111:5944-5972. [PubMed: 21861450]

(7). Esterbauer H, Schaur RJ, Zollner H. Chemistry and biochemistry of 4-hydroxynonenal, malonaldehyde and related aldehydes. Free Radical Biol. Med. 1991; 11:81-128. [PubMed: 1937131]

(8). Ullery JC, Marnett LJ. Protein modification by oxidized phospholipids and hydrolytically released lipid electrophiles: Investigating cellular responses. Biochim. Biophys. Acta, Biomembr. 2012; 1818:2424-2435.

(9). Ekholm SV, Reed SI. Regulation of g(1) cyclin-dependent kinases in the mammalian cell cycle. Curr. Opin. Cell Biol. 2000; 12:676-684. [PubMed: 11063931]

(10). Lees E, Faha B, Dulic V, Reed SI, Harlow E. Cyclin e/cdk2 and cyclin a/cdk2 kinases associate with p107 and e2f in a temporally distinct manner. Genes Dev. 1992; 6:1874-1885. [PubMed: 1398067]

(11). Harbour JW, Luo RX, Dei Santi A, Postigo AA, Dean DC. CDK phosphorylation triggers sequential intramolecular interactions that progressively block rb functions as cells move through G1. Cell. 1999; 98:859-869. [PubMed: 10499802]

(12). Giacinti C, Giordano A. Rb and cell cycle progression. Oncogene. 2006; 25:5220-5227. [PubMed: 16936740]

(13). Harper JW, Adami GR, Wei N, Keyomarsi K, Elledge SJ. The p21 cdk-interacting protein cip1 is a potent inhibitor of g1 cyclin-dependent kinases. Cell. 1993; 75:805-816. [PubMed: 8242751]

(14). Wang Y, Fisher JC, Mathew R, Ou L, Otieno S, Sublet J, Xiao L, Chen J, Roussel MF, Kriwacki RW. Intrinsic disorder mediates the diverse regulatory functions of the cdk inhibitor $\mathrm{p} 21$. Nat. Chem. Biol. 2011; 7:214-221. [PubMed: 21358637]

(15). Barrera G, Pizzimenti S, Dianzani MU. 4-hydroxynonenal and regulation of cell cycle: Effects on the prb/e2f pathway. Free Radical Biol. Med. 2004; 37:597-606. [PubMed: 15288118]

(16). Wonisch W, Kohlwein SD, Schaur J, Tatzber F, Guttenberger H, Zarkovic N, Winkler R, Esterbauer $\mathrm{H}$. Treatment of the budding yeast saccharomyces cerevisiae with the lipid peroxidation product 4-hne provokes a temporary cell cycle arrest in g1 phase. Free Radical Biol. Med. 1998; 25:682-687. [PubMed: 9801068]

(17). Barrera G, Pizzimenti S, Muraca R, Barbiero G, Bonelli G, Baccino FM, Fazio VM, Dianzani MU. Effect of 4-hydroxynonenal on cell cycle progression and expression of differentiationassociated antigens in hl-60 cells. Free Radical Biol. Med. 1996; 20:455-462. [PubMed: 8720918] 
(18). Laurora S, Tamagno E, Briatore F, Bardini P, Pizzimenti S, Toaldo C, Reffo P, Costelli P, Dianzani MU, Danni O, Barrera G. 4-hydroxynonenal modulation of p53 family gene expression in the sk-n-be neuroblastoma cell line. Free Radical Biol. Med. 2005; 38:215-225. [PubMed: 15607904]

(19). Codreanu SG, Zhang B, Sobecki SM, Billheimer DD, Liebler DC. Global analysis of protein damage by the lipid electrophile 4-hydroxy-2-nonenal. Mol. Cell. Proteomics. 2009; 8:670-680. [PubMed: 19054759]

(20). Vila A, Tallman KA, Jacobs AT, Liebler DC, Porter NA, Marnett LJ. Identification of protein targets of 4-hydroxynonenal using click chemistry for ex vivo biotinylation of azido and alkynyl derivatives. Chem. Res. Toxicol. 2008; 21:432-444. [PubMed: 18232660]

(21). Codreanu SG, Ullery JC, Zhu J, Tallman KA, Beavers WN, Porter NA, Marnett LJ, Zhang B, Liebler DC. Alkylation damage by lipid electrophiles targets functional protein systems. Mol. Cell. Proteomics. 2014; 13:849-859. [PubMed: 24429493]

(22). Zhang B, Shi Z, Duncan DT, Prodduturi N, Marnett LJ, Liebler DC. Relating protein adduction to gene expression changes: A systems approach. Mol. BioSyst. 2011; 7:2118-2127. [PubMed: 21594272]

(23). McGrath CE, Tallman KA, Porter NA, Marnett LJ. Structure-activity analysis of diffusible lipid electrophiles associated with phospholipid peroxidation: 4-hydroxynonenal and 4-oxononenal analogues. Chem. Res. Toxicol. 2011; 24:357-370. [PubMed: 21291287]

(24). van den Heuvel S, Harlow E. Distinct roles for cyclin-dependent kinases in cell cycle control. Science. 1993; 262:2050-2054. [PubMed: 8266103]

(25). Schonthal AH. Measuring cyclin-dependent kinase activity. Methods Mol. Biol. 2004; 281:105124. [PubMed: 15220524]

(26). Weerapana E, Wang C, Simon GM, Richter F, Khare S, Dillon MB, Bachovchin DA, Mowen K, Baker D, Cravatt BF. Quantitative reactivity profiling predicts functional cysteines in proteomes. Nature. 2010; 468:790-795. [PubMed: 21085121]

(27). Xu M, Sheppard KA, Peng CY, Yee AS, Piwnica-Worms H. Cyclin a/cdk2 binds directly to e2f-1 and inhibits the DNA-binding activity of e2f-1/dp-1 by phosphorylation. Mol. Cell. Biol. 1994; 14:8420-8431. [PubMed: 7969176]

(28). Sheaff RJ, Groudine M, Gordon M, Roberts JM, Clurman BE. Cyclin e-cdk2 is a regulator of p27kip1. Genes Dev. 1997; 11:1464-1478. [PubMed: 9192873]

(29). Akiyama T, Ohuchi T, Sumida S, Matsumoto K, Toyoshima K. Phosphorylation of the retinoblastoma protein by cdk2. Proc. Natl. Acad. Sci. U. S. A. 1992; 89:7900-7904. [PubMed: 1518810]

(30). Sampey BP, Carbone DL, Doorn JA, Drechsel DA, Petersen DR. 4-hydroxy-2-nonenal adduction of extracellular signal-regulated kinase (erk) and the inhibition of hepatocyte erk-est-like protein-1-activating protein-1 signal transduction. Mol. Pharmacol. 2007; 71:871-883. [PubMed: 17164404]

(31). Barrera G, Pizzimenti S, Laurora S, Moroni E, Giglioni B, Dianzani MU. 4-hydroxynonenal affects prb/e2f pathway in hl-60 human leukemic cells. Biochem. Biophys. Res. Commun. 2002; 295:267-275. [PubMed: 12150942]

(32). Sharma A, Sharma R, Chaudhary P, Vatsyayan R, Pearce V, Jeyabal PV, Zimniak P, Awasthi S, Awasthi YC. 4-hydroxynonenal induces p53-mediated apoptosis in retinal pigment epithelial cells. Arch. Biochem. Biophys. 2008; 480:85-94. [PubMed: 18930016]

(33). Gu Y, Rosenblatt J, Morgan DO. Cell cycle regulation of cdk2 activity by phosphorylation of thr160 and tyr15. EMBO J. 1992; 11:3995-4005. [PubMed: 1396589]

(34). Ji C, Amarnath V, Pietenpol JA, Marnett LJ. 4-hydroxynonenal induces apoptosis via caspase-3 activation and cytochrome c release. Chem. Res. Toxicol. 2001; 14:1090-1096. [PubMed: 11511183]

(35). Macleod KF, Sherry N, Hannon G, Beach D, Tokino T, Kinzler K, Vogelstein B, Jacks T. P53dependent and independent expression of p21 during cell growth, differentiation, and DNA damage. Genes Dev. 1995; 9:935-944. [PubMed: 7774811]

(36). Sayre LM, Lin D, Yuan Q, Zhu X, Tang X. Protein adducts generated from products of lipid oxidation: Focus on hne and one. Drug Metab. Rev. 2006; 38:651-675. [PubMed: 17145694] 
(37). Russo AA, Jeffrey PD, Pavletich NP. Structural basis of cyclin-dependent kinase activation by phosphorylation. Nat. Struct. Biol. 1996; 3:696-700. [PubMed: 8756328]

(38). Honda R, Lowe ED, Dubinina E, Skamnaki V, Cook A, Brown NR, Johnson LN. The structure of cyclin e1/ cdk2: Implications for cdk2 activation and cdk2-independent roles. EMBO J. 2005; 24:452-463. [PubMed: 15660127]

(39). Fisher RP, Morgan DO. A novel cyclin associates with mo15/cdk7 to form the cdk-activating kinase. Cell. 1994; 78:713-724. [PubMed: 8069918]

(40). Chi Y, Welcker M, Hizli AA, Posakony JJ, Aebersold R, Clurman BE. Identification of cdk2 substrates in human cell lysates. Genome Biol. 2008; 9:R149. [PubMed: 18847512]

(41). Grafstrom RH, Pan W, Hoess RH. Defining the substrate specificity of cdk4 kinase-cyclin d1 complex. Carcinogenesis. 1999; 20:193-198. [PubMed: 10069453] 


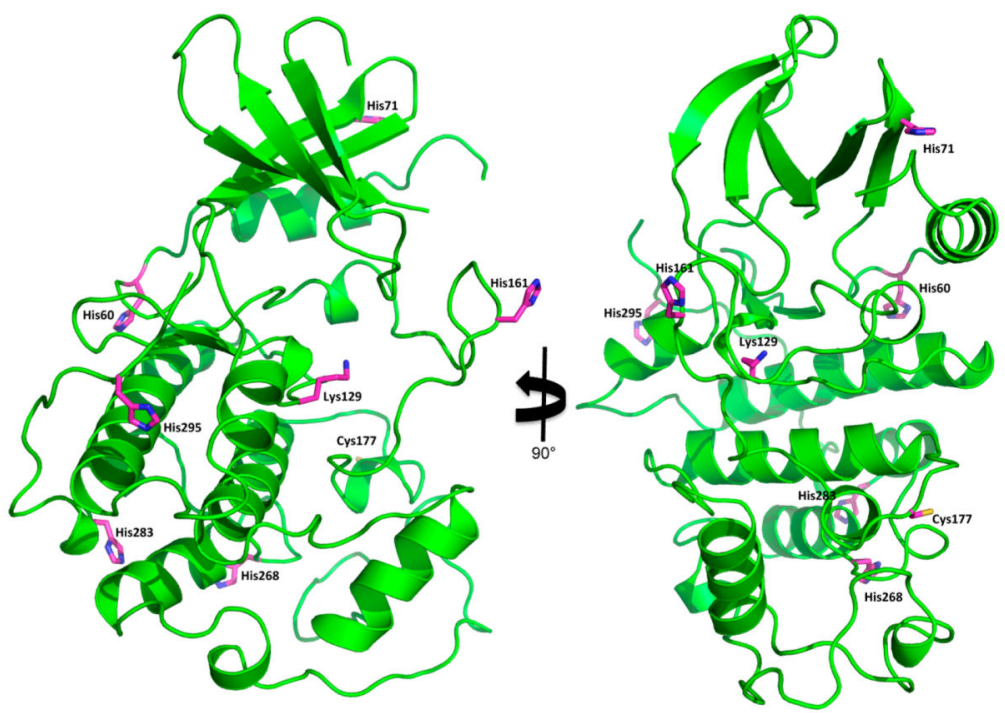

Figure 1.

Recombinant CDK2 is modified by HNE at a number of sites. Crystal structure of unphosphorylated CDK2 (PDB ID: 1HCL) with residues modified by HNE in magenta. 
A)

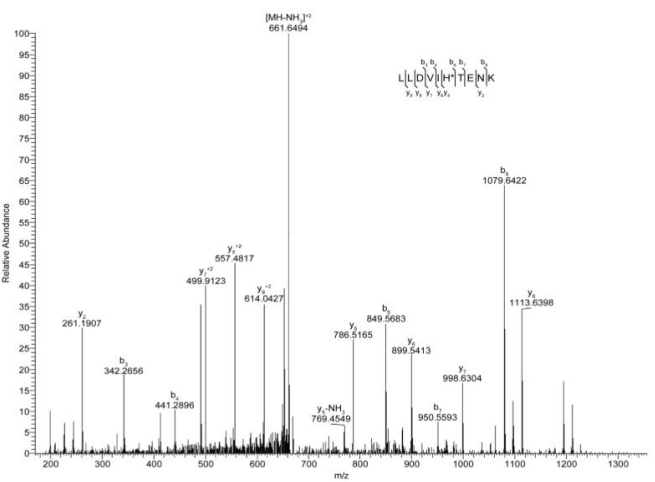

B)

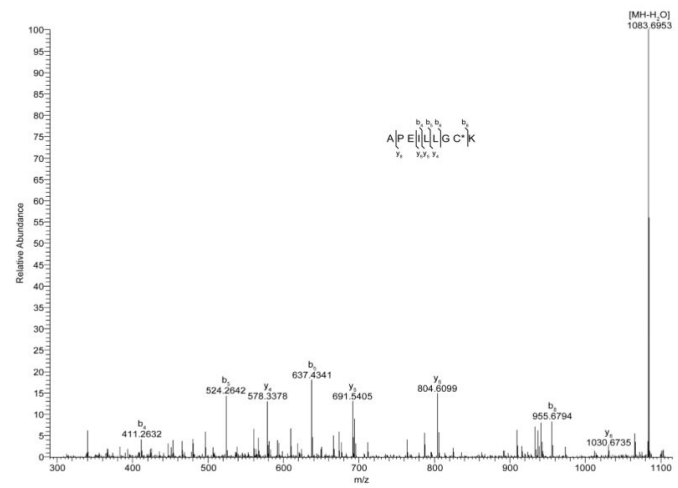

Figure 2.

CDK2 is modified by HNE in cells. Tandem mass spectrometry was performed on CDK2His from HNE-treated RKO cells. (A) MS ${ }^{2}$ spectrum of LLDVIH*TENK. (B) MS ${ }^{2}$ spectrum of APEILLGC*K. Sites of modification are represented by an asterisk (*). 
A)

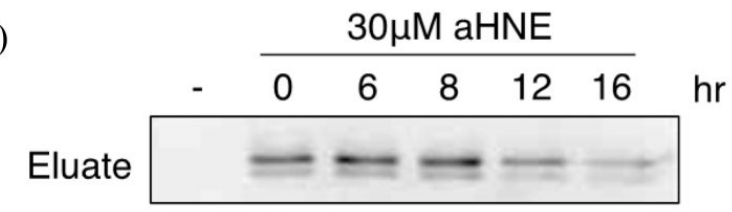

$1 \%$ Input $=\overline{=}=$

B)

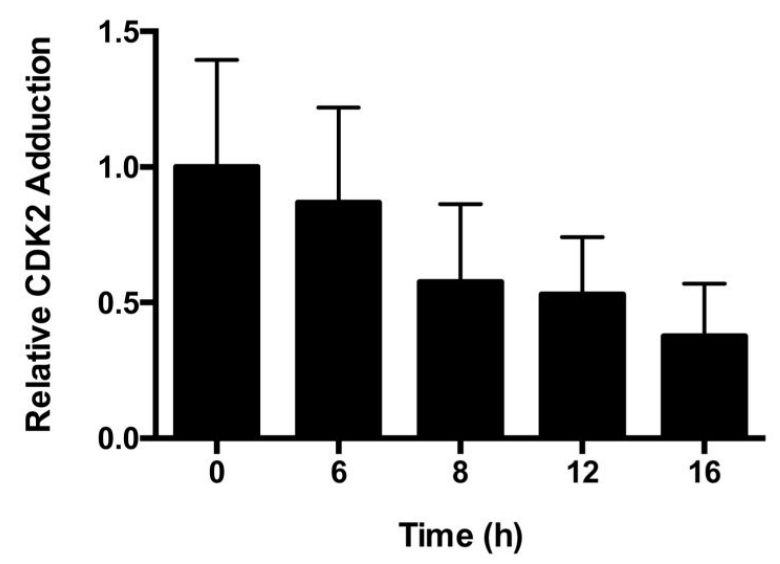

Figure 3.

aHNE modifies CDK2 in RKO Cells. RKO cells were serum starved for $24 \mathrm{~h}$ to synchronize them in G0/G1, and then they were treated for $1 \mathrm{~h}$ with $30 \mu \mathrm{M}$ aHNE or DMSO. Treatment medium was removed, and $10 \%$ serum-containing medium was added to allow the cells to enter into the cell cycle. Cells were collected at the indicated times, and lysates were subjected to click chemistry and streptavidin pull down. UV eluates and $1 \%$ input were subjected to SDS-PAGE and Western blotting. (A) Western blotting shows that levels of aHNE-modified CDK2 decline over time after the initial treatment, whereas levels of total CDK2 remain unchanged. (B) Densitometry of adducted CDK2 normalized to the $0 \mathrm{~h}$ eluate. 
A)

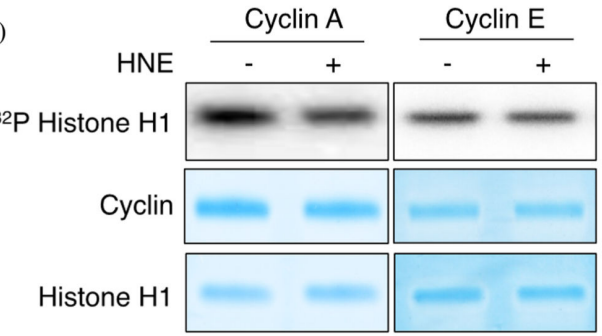

B)

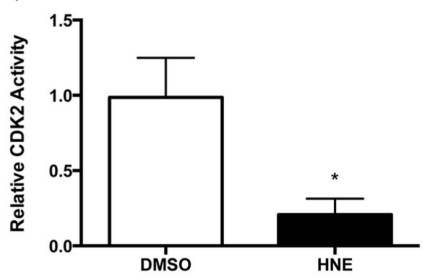

C)

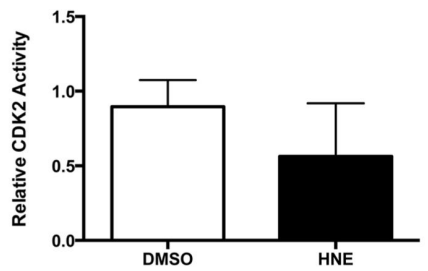

Figure 4.

HNE treatment lowers CDK2 activity in vitro. Recombinant CDK2 protein with Cyclin A or Cyclin E was modified in vitro with $30 \mu \mathrm{M}$ HNE. (A) Kinase assays followed by autoradiography show an HNE-mediated decrease in CDK2 activity with Cyclin A but not Cyclin E. Quantification of CDK2 activity with (B) Cyclin A and (C) Cyclin E represents the mean $\pm \mathrm{SD}(n=3), * p<0.05$. 

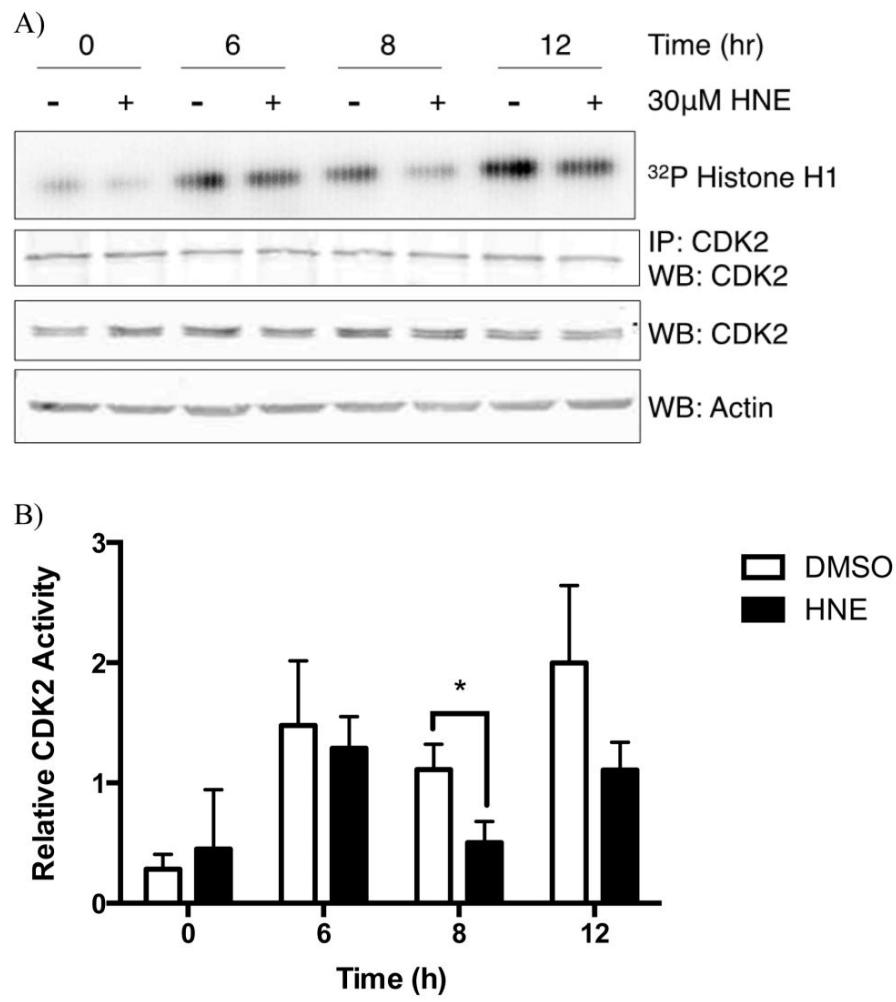

Figure 5.

HNE treatment decreases CDK2 activity in cells. CDK2 was immunoprecipitated from RKO cells treated with HNE and subjected to kinase assays. (A) CDK2 from cells treated with HNE shows a decrease in kinase activity at 8 and 12 h. (B) Quantification of CDK2 activity representing the mean $\pm \mathrm{SD}(n=3)$. The difference in kinase activity was statistically significant at $8 \mathrm{~h}(* p<0.05)$ but not $12 \mathrm{~h}$. 


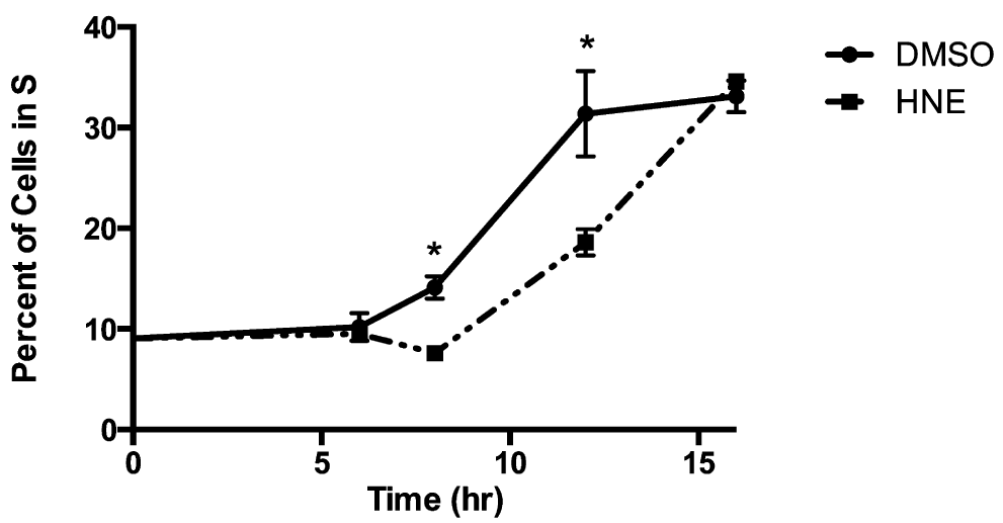

Figure 6.

HNE delays entry into S-phase. RKO cells were serum-starved for $24 \mathrm{~h}$ to synchronize them in $\mathrm{G} 0 / \mathrm{G} 1$ and then treated for $1 \mathrm{~h}$ with $30 \mu \mathrm{M}$ HNE or DMSO. Medium containing $10 \%$ serum was added to allow the cells to enter into the cell cycle. Cells were collected at the indicated times, and the cell cycle phase was analyzed by flow cytometry. The data represent the mean $\pm \mathrm{SD}(n=6 ; * p<0.05$ between HNE- and DMSO-treated using one-way ANOVA with Bonferroni post-test). 


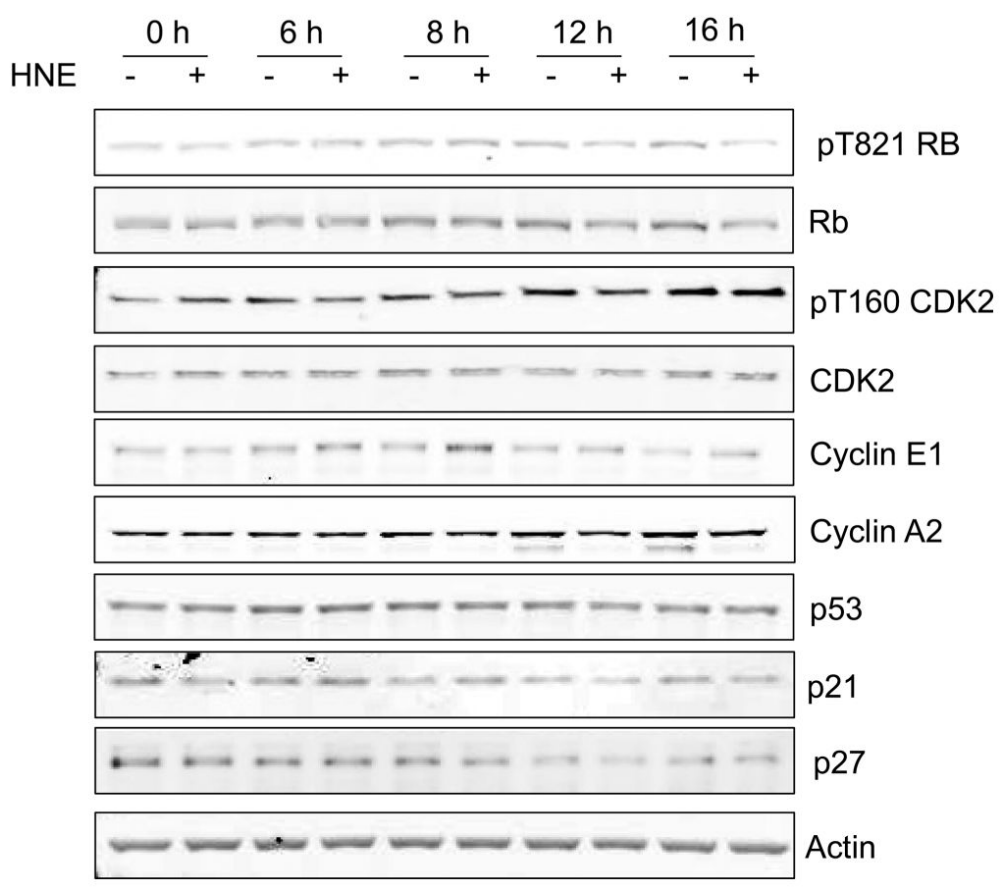

Figure 7.

HNE does not alter levels of total or phosphorylated cell cycle proteins. RKO cells were serum-starved for $24 \mathrm{~h}$ to synchronize them in G0/G1 and then treated for $1 \mathrm{~h}$ with $30 \mu \mathrm{M}$ HNE or DMSO. Medium containing $10 \%$ serum was added to allow the cells to enter into the cell cycle. Cells were collected at the indicated times and analyzed for expression of G1/S-phase proteins. 

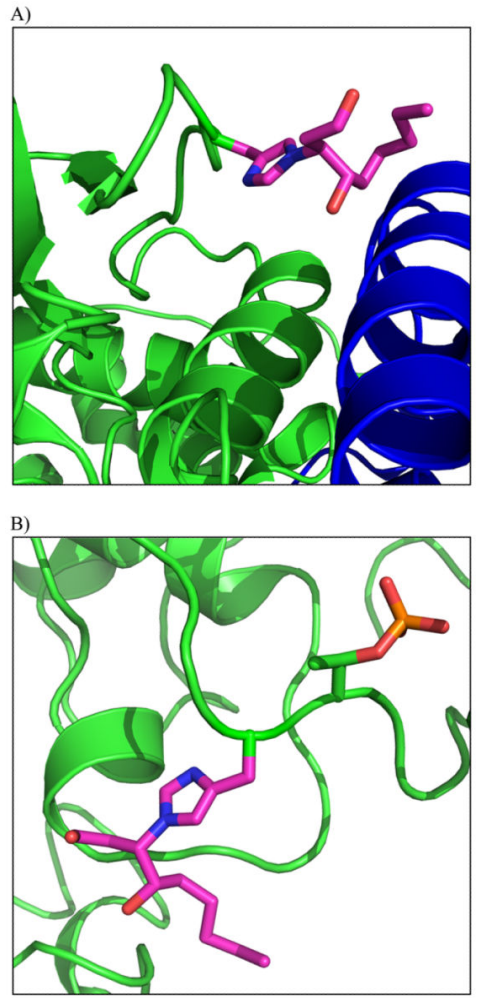

Figure 8.

Modeling of HNE adducts on CDK2. HNE adducts (magenta) were modeled onto (A) His71 of CDK2 in the CDK2 (green) with Cyclin E (blue) structure (1W98) and (B) His161 in the phosphorylated Thr160 structure of CDK2 (4EOM). 


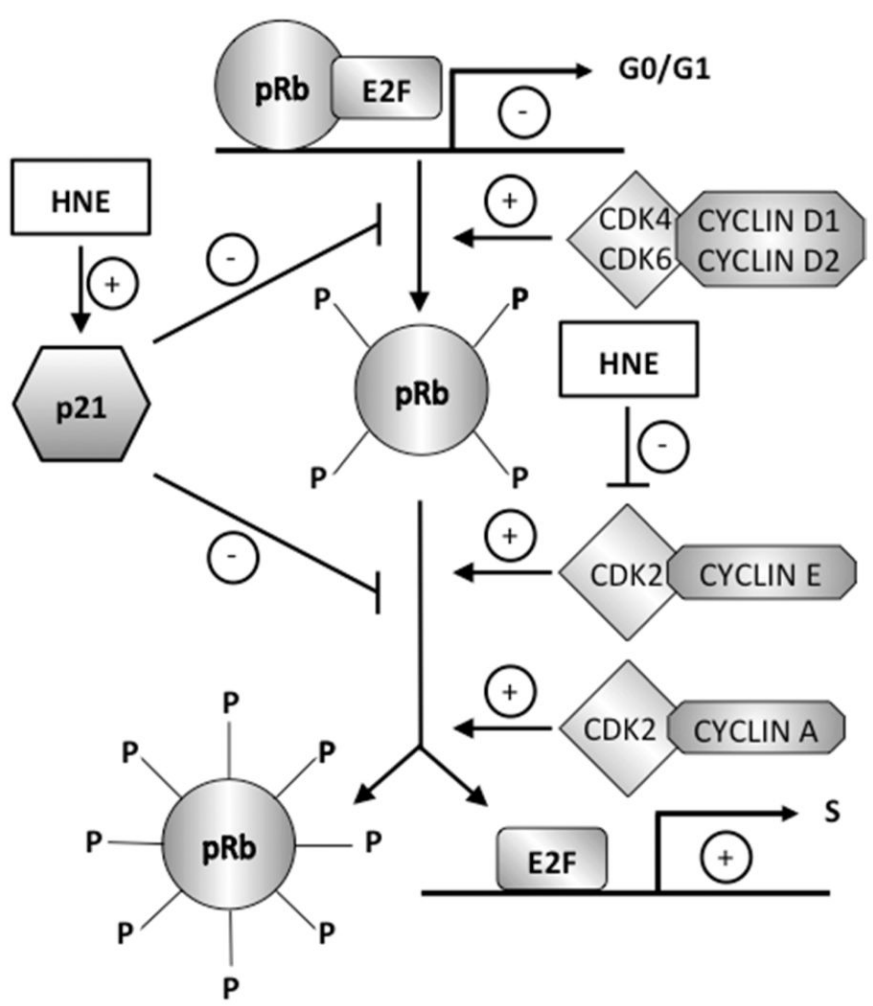

Figure 9.

Proposed mechanism for the delay in S-phase entry. Under normal conditions, Rb remains bound to E2F until the G1 CDKs phosphorylate it, allowing for transcription of S-phase genes. Our model suggests that HNE covalently modifies CDK2, decreasing its activity toward $\mathrm{Rb}$ and delaying S-phase entry. 


\section{Table 1}

Sites of HNE Modification on Recombinant CDK2 Identified by LC-MS/MS ${ }^{a}$

\begin{tabular}{lccccccc}
\hline \multicolumn{1}{c}{ peptide } & residue modified & XCorr & observed $\boldsymbol{m} / \boldsymbol{z}$ & charge & mass error (ppm) & peptide start-stop & observed spectra \\
\hline ELNH*PPNIVK & His60 & 3.15 & 611.3672 & 2 & 0.33 & $57-65$ & 3 \\
LLDVIH*TENK & His71 & 3.12 & 670.3999 & 2 & 0.15 & $66-75$ & 4 \\
DLK*PQNLLINTEGAIK & Lys129 & 3.55 & 642.3870 & 3 & 0.00 & $127-142$ & 2 \\
TYTH*EVVTLWYR & His161 & 3.18 & 863.4668 & 2 & 0.17 & $158-169$ & 8 \\
SLLSQMLH*YDPNKR & His268 & 3.45 & 620.6743 & 3 & 0.32 & $261-273$ & 2 \\
AALAH*PFFQDVTK & His283 & 2.13 & 534.9724 & 3 & 0.37 & $279-291$ & 7 \\
PVPH*LR & His295 & 1.89 & 438.7900 & 1 & 1.82 & $292-298$ & 4
\end{tabular}

${ }^{a}$ Recombinant CDK2 was modified in vitro with $30 \mu \mathrm{M}$ HNE and analyzed for sites of HNE adduction by tandem mass spectrometry in three independent experiments. Modified residues are indicated by an asterisk. Data shown in the table represent the adducted peptides with the lowest mass error. 
Table 2

Sites of HNE Modification on Endogenous CDK2 Identified by LC-MS/MS ${ }^{a}$

\begin{tabular}{lccccccc}
\hline peptide & residue modified & XCorr & observed $\boldsymbol{m} / \boldsymbol{z}$ & charge & mass error $(\mathbf{p p m})$ & peptide start-stop & observed spectra \\
\hline LLDVIH*TENK & His71 & 3.58 & 670.3919 & 2 & 4.92 & $66-75$ & 3 \\
APEILLGC $* \mathrm{~K}$ & Cys177 & 2.87 & 1101.6543 & 1 & 3.99 & $170-178$ & 5
\end{tabular}

${ }^{a}$ RKO cells were transfected with CDK2-His and treated with HNE. Following isolation of His-tagged proteins and separation by SDS-PAGE, bands corresponding to CDK2-His were excised, subjected to in-gel digestion, and analyzed by tandem mass spectrometry. Modified residues are indicated by an asterisk. Data shown in the table represent the adducted peptides with the lowest mass error. 